\title{
Elucidating the Physio-Morphological and Biochemical Responses towards PEG-Induced Drought Stress in Finger Millet Genotypes
}

\author{
Gautam Jamra ${ }^{1}$, Pallavi Shah ${ }^{1}$, Aparna Agarwal $^{1}$, Divya Sharma ${ }^{1}$ and Anil Kumar ${ }^{1,2} *$ \\ ${ }^{1}$ G.B. Pant University of Agriculture and Technology, Pantnagar, US Nagar, \\ Uttarakhand -263145, India \\ ${ }^{2}$ Director of Education, Rani Lakshmi Bai Central Agriculture University, Jhansi, NH-75, \\ Near Pahuj Dam, Gwalior Road, Jhansi, UttarPradesh-284003, India \\ *Corresponding author
}

\begin{tabular}{|l|}
\hline Ke y w or d s \\
Water deficit, \\
Genotypes, \\
Tolerant, \\
Susceptible, PEG \\
(Poly Ethylene \\
Glycol)
\end{tabular}

A B S T R A C T

Drought stress is a key restraint to crop productivity worldwide, specifically in arid and semi-arid regions. It can lead to physiological and biochemical changes ultimately leading to oxidative burst. Finger millet, often considered an orphan crop, is known to be drought tolerant and a rich source of calcium. In the present work, responses of four finger millet varieties, at seedling stage, to PEG-induced moderate and extreme water stress have been documented. Physiological and biochemical aspects were studied based on which the finger millet varieties were designated as drought tolerant and sensitive. On enhancing the degree of water stress, significant $(\mathrm{p}<0.01)$ reduction in the physiological parameters was observed followed by enhanced accumulation of antioxidant enzymes. Moreover, we found GP-45 and GE-1437 as tolerant genotypes, which showed better drought tolerance as expressed by the chosen parameters in comparison to the susceptible GP-1 and GE-3885. The results lead us to speculate that inherent nutrient and genetic variation may play a role in drought tolerance. The tolerant varieties maintain theirnutritional value and ROS homeostasis. In future, it will be interesting to explore the biochemical and molecular mechanisms involved in drought tolerance and susceptible responsiveness for further crop improvement.

\section{Introduction}

The inability to change their environment in plants has led to adaptation to cope up with continuously changing and often unfavourable environmental conditions. These conditions include different kinds of abiotic stresses that emanate from either deficit or excess of optimal temperature, water and light in the environment and several biotic stresses inflicted by organisms, such as fungi, bacteria, viruses and insects (Boyer, 1982; Hadiarto and Tran, 2010; Onada and Wydra, 2016). Water deficit is a major 
problem for agriculture in regards to climate change combined with an increasing demand for food (Lobell et al., 2014). Drought is a calamity for agriculture, humanity, and livestock allied with climate change driving us towards a hotter, more parched world (FAO, 2019). There is an imperative need to produce high-yielding plants that use water more efficiently than present-day counterparts (Gupta et al., 2020).

Polyethylene Glycol (PEG), due to its high molecular weight, is often used to elicit water stress in vitro. It acts as a non-penetrating, non-ionic, inert osmoticum, which reduces the water potential of nutrient medium without being toxic (Hassan et al., 2004).Water stress leads to enhanced production of reactive oxygen species (ROS) and therefore has adverse impacts on cellular structure and metabolism. To scavenge these increased levels of ROS, several enzymes such as superoxide dismutase (SOD), catalase (CAT), peroxidase (POD) and non-enzymatic antioxidant systems like ascorbate (AsA), and glutathione (GSH) have evolved in plants (Sharma et al., 2012). Assessment of such antioxidant parameters is thus carried out in vitro to evaluate the stress responses of plants (You and Chan 2015; Asaeda et al., 2017). Several studies have correlated antioxidant defence mechanism with plant resistance to withstand drought stress (Ren et al., 2016). Superoxide radicals $\left(\mathrm{O}_{2}{ }^{-}\right)$gets converted to hydrogen peroxide $\left(\mathrm{H}_{2} \mathrm{O}_{2}\right)$ by $\mathrm{SOD}$ and utilizing different electron donors, $\mathrm{H}_{2} \mathrm{O}_{2}$ is reduced to water by POD; ascorbate reduces $\mathrm{H}_{2} \mathrm{O}_{2}$ to water and CAT breaks down $\mathrm{H}_{2} \mathrm{O}_{2}$ into oxygen and water (Khan et al., 2019).

Finger millet (Eleusine coracana (L.) Gaertn.) is an annually growing monocot crop, extensively cultivated and consumed by the population in African and Asian continents. It consists of protein, minerals and other nutrients in rich amounts compared to other major cereals such as rice and wheat (Gupta et al., 2017). Finger millet is exceptionally rich in calcium $(\mathrm{Ca})$ content with as high as $0.34 \%$ in whole seeds (Sharma et al., 2017). Nutrient deficiencies, salinity and drought have been shown to influence finger millet production (Ramakrishnan et al., 2017; Maharajan et al., 2018). Drought is also a major abiotic constraint for finger millet production as it induces wilting and leaf rolling (Parvathi et al., 2013). Finger millet is a rigid crop with exceptional stress tolerance potential aided by its ability to sustain under water-deficit conditions. A significant level of inter-varietal disparity is seen in finger millet varieties in terms of drought tolerance and very limited work has hitherto been done in this regard(Uma et al., 1995). Identifying biochemical and physiological changes involved in the regulation of drought tolerance, aided with genetic improvement techniques, can help develop varieties with better adaption to abiotic stresses (Shanker et al., 2014)

Though finger millet is known to be droughttolerant, previous studies have shown it to be susceptible to various abiotic stresses, especially water stress at germination and early developmental stages of the seedlings (Saha et al., 2016; Parvathi and Nataraja, 2017). Present work has been carried out to gain further information on the morphological and biochemical changes in seedlings of finger millet. A combined physiological and biochemical strategy has been utilized to evaluate tolerance to drought in different finger millet genotypes via quantitative plant growth and enzymatic antioxidants parameters. The present investigation aims to improve the understanding of underlying responses of different finger millet genotypes to drought stress and to decipher the mechanisms of drought resistance. This study will help enunciate the importance of inherent tolerance trait in breeding and introgression 
programmes for selection and development of drought tolerant finger millet to improve crop yield in arid and semi-arid regions.

\section{Materials and Methods}

Plant material and estimation of post germination based morphological analysis under differential PEG stress

Four finger millet genotypes were used in the present investigation (Table 1). Selection of seeds was based on size homogeneity. They were further surface-sterilized for $5 \mathrm{~min}$ in $0.1 \%(\mathrm{w} / \mathrm{v}) \mathrm{HgCl}_{2}$, rinsed and soaked in distilled water for $1 \mathrm{~h}$. For, post germination based phenotypic studies 5 days old seedlings grown on $1 / 2$ MS medium were transferred to different stress media [distilled water or 5,10 , 15, 20 and 25\% of PEG (MW-6000)]. Physiological parameters were recorded after 4-5 days while biochemical parameters were assessed after 48 hours of treatment. Plants were grown at a temperature of $27 \pm 1^{\circ} \mathrm{C}$ with a relative humidity of $70 \%$ under dark conditions.

\section{Estimation of physiological parameters}

Data for physiological parameters such as fresh weight $(\mathrm{mg})$, shoot length $(\mathrm{cm})$, root length $(\mathrm{cm})$ and relative water content (RWC) was collected after four days in triplicate for each genotype. The RWC was measured and expressed as percentage according to the formula

RWC $(\%)=($ Fresh Weight - Dry Weight / Fresh Weight) *100.

\section{Estimation of antioxidant enzymes}

\section{Enzyme extraction}

Antioxidant enzyme activities were determined by homogenising $500 \mathrm{mg}$ seedlings in chilled extraction buffer containing Triton X-100 (0.5 \%) and polyvinylpyrrolidone $(1 \%)$ in phosphate buffer (100 mM, pH 7.0). The mixture was centrifuged, at 12,000 rpm for $30 \mathrm{~min}$ at $4^{\circ} \mathrm{C}$ and the supernatant was used to assay activity of antioxidant enzymes (Askari and Ehsanzadeh 2015). In all the enzyme preparations protein was determined by Bradford's method (Bradford 1976) using bovine serum albumin (BSA, Sigma) as standard.

\section{Catalase (CAT) assay}

The catalase activity was determined according to the method given by Beers and Sizer (1952). $2 \mathrm{ml}$ assay mixture contained 21.5mM phosphate buffer ( $\mathrm{pH} 7.0), 40 \mathrm{mM}$ $\mathrm{H}_{2} \mathrm{O}_{2}$ and $100 \mu \mathrm{l}$ enzyme extract. The decrease in $\mathrm{H}_{2} \mathrm{O}_{2}$ amount was monitored at $240 \mathrm{nM}$ by decrease in absorbance (extinction coefficient $0.036 \mathrm{mM}^{-1} \mathrm{~cm}^{-1}$ ). The enzyme activity was shown as $\mu \mathrm{mol}$ of $\mathrm{H}_{2} \mathrm{O}_{2}$ oxidized per min per mg of protein.

\section{Guaiacol peroxidase (POD) assay}

$5 \mathrm{ml}$ enzyme assay mixture contained phosphate buffer (40 mM, pH 6.1), $\mathrm{H}_{2} \mathrm{O}_{2}$ (2 $\mathrm{mM})$, guaiacol $(9 \mathrm{mM})$ and enzyme $(50 \mu \mathrm{l})$. The increase in absorbance $(420 \mathrm{~nm}$, extinction coefficient $26.6 \mathrm{mM}^{-1} \mathrm{~cm}^{-1}$ ) was recorded at intervals of $30 \mathrm{~s}$ up to $2 \mathrm{~min}$. The enzyme activity was shown as $\mu$ mol of $\mathrm{H}_{2} \mathrm{O}_{2}$ reduced per min per $\mathrm{mg}$ of protein (Zaharieva et al., 1999).

\section{Ascorbate peroxidase (APX) assay}

The method stated by Nakano and Asada (1981) was used for determination of APX activity. The reaction mixture consisted of phosphate buffer (50 mM, pH 7.0), ascorbic acid (0.2 mM), EDTA (0.2 $\mathrm{mM})$ and enzyme prepared followed by addition of $\mathrm{H}_{2} \mathrm{O}_{2}$. 
Decrease in the absorbance at $290 \mathrm{~nm}$ (extinction coefficient $2.8 \mathrm{mM}^{-1} \mathrm{~cm}^{-1}$ ) was recorded at intervals of $30 \mathrm{~s}$ up to $7 \mathrm{~min}$. The enzyme activity was shown as $\mu \mathrm{mol}$ ascorbate oxidized per min per mg of protein.

\section{Superoxide Dismutase (SOD) assay}

The SOD activity was determined by measuring inhibition of photoreduction of nitro blue tetrazolium (NBT) according to the method of Dhindsa et al., 1981. Reaction mixture containing phosphate buffer $(50 \mathrm{mM}$, $\mathrm{pH} 7.8)$, methionine (13mM), NBT (50 mM), EDTA $(75 \mu \mathrm{M})$, riboflavin $(1.3 \mathrm{M})$, and enzyme $(50 \mu l)$ was irradiated under fluorescent light for $15 \mathrm{~min}$. At $560 \mathrm{~nm}$ absorbance was recorded against nonirradiated reaction buffer as a blank. One unit of SOD activity was expressed as the amount of enzyme that inhibited $50 \%$ of NBT photo reduction.

\section{Statistical analysis}

All analysis was done by two-way ANOVA and the means are compared by using Bonferroni test at $5 \%$ statistically significance which was defined as a $P$ value $\leq 0.05$. All the results were represented as mean \pm standard error of mean (SEM) $(n=2)$.

\section{Results and Discussion}

\section{Phenotypic analysis under drought stress post germination}

Phenotypes of 5 days old seedlings of four finger millet genotypes i.e. GP-45, GE-1437, GP-1 and GE-3885, under 5, 10, 15 and 20 $\%$ PEG treatments were recorded on $5^{\text {th }}$ day after treatment. Among all genotypes, GP-45 was found to be significantly $(\mathrm{P} \leq 0.05)$ tolerant showing normal growth i.e. healthy, green seedlings with well-developed root system even up to $15 \%$ PEG exposure followed by GE-1437 also showing a normal phenotype up to $15 \%$ PEG treatment[Figure 1(A) and (B)].However, GP-1 and GE-3885 could tolerate only up to $10 \%$ PEG treatment showing sensitive morphological response i.e. poor stunted growth, sensitive, pale yellow and poorly developed root system when treated with 15\% PEG [Figure1(C) and (D)].

\section{Seedling growth analysis under PEG treatment}

Seedling growth of the four finger millet genotypes was evaluated under the different PEG concentrations mentioned above. Among all the genotypes, GP-45 and GE-1437 showed better tolerance in comparison to GP1 and GE-3885, which showed sensitivity towards moderate and extreme drought stress. Under drought stress, fresh weight of stressed seedlings was found to be reduced on increasing PEG concentration [Figure 2 (A)]. There was drastic reduction in fresh weight of GP-1 and GE-3885 seedlings after 10\% PEG treatment whereas GP-45 and GE-1437 showed reduction at $15 \%$ PEG and higher concentrations.GP-45 and GE-1437 also recorded significantly $(\mathrm{P}<0.05)$ healthier and longer root and shoot in comparison to GP-1 and GE-3885 under different PEG treatments [Figure 2(B) and (C)]

\section{Relative water content under PEG treatment}

The relative water content (RWC) of all finger millet genotypes decreased with increasing PEG concentration [Figure 2 (D)]. Under control condition i.e. 0\% PEG, RWC of GP-45 and GE-1437 was slightly more than GP-1 and GE-3885. On increasing PEG treatment $(5-25 \%)$ there was reduction in RWC in all the four genotypes. However, GP45 and GE-1437 had less depletion in comparison to GP-1 and GE-3885. There was significant decline in RWC in comparison to 
control at $25 \%$ PEG treatment for all four genotypes. Based on seedling growth and morphological analysis of finger millet genotypes, 0 to $25 \%$ PEG induced osmotic stress was used for further experiments.

\section{Estimation of enzymatic antioxidants}

In finger millet seedlings, antioxidant enzyme (CAT, POD, APX andSOD) activities varied significantly $(\mathrm{P} \leq 0.05)$ in response to stress induced by drought in both drought-resistant and sensitive genotypes.

In general, the $\mathrm{H}_{2} \mathrm{O}_{2}$ scavenging enzyme (CAT, SOD, APX and POD) activities were evaluated in different genotypes exposed to increased water-deficit stress treatments from 0-25\% PEG. CAT activity was elevated significantly in all genotypes however; activity was comparatively higher in GP$45(\sim 2.5$ fold $)$ and GE-1437( 2.0 fold $)$ genotypes in comparison to GP-1( 1.5 fold $)$ and GE-3885( 1.5 fold) [Figure 3(A)]. There was gradual comparative increase in CAT activity for 0 to $15 \%$ PEG treatment whereas a drastic increase after $15 \%$ PEG treatment was observed for all four genotypes.

Under drought stress, on increasing PEG treatments elevation in POD activity was observed. Significant increase in POD activity was observed in GP-45. POD activity was comparatively higher in GP-45 than other genotypes GE-1437 >GP-1>GE-3885 respectively [Figure 3(B)]. There was no significant change in POD activity of GP-1 and GE-3885 on exposure of $0-15 \%$ PEG treatments. However, significant increase in POD activity was observed in $25 \%$ PEG treatments.

APX activity, similarly, increased with increase in the water-deficit condition and significant elevation was observed in GP-45 in relevance to other genotypes. GP-45 demonstrated comparatively higher APX activity in all treatments while others also showed same trend but not as significantly as GP-45[Figure 3 (C)]. Among all the genotypes, APX activity was found to be the highest inGP-45 and GE-1437 at 25\% PEG while in GP-1 and GE-3885, no significant changes were observed in all the PEG treatments.

All genotypes showed almost similar SOD activity under control growth condition (0\%PEG).Nevertheless, on increasing PEG stress, increased SOD activity was observed [Figure 3 (D)]. However, comparatively higher SOD activity with increasing PEG treatments was observed for GP-45 and GE1437 compared to GP-1 and GE-3885.

Table.1 Finger millet genotypes used in the experiment

\begin{tabular}{|c|c|}
\hline Genotypes & Inherent nutritional content \\
\hline GP-45 & High Calcium \\
\hline GP-1 & Low Calcium \\
\hline GE-1437 & Low Protein \\
\hline GE-3885 & High Protein \\
\hline
\end{tabular}


Figure.1 Effect of PEG-mediated drought stress on the phenotype of different genotypes of finger millet seedlings post germination. (A) GP-45; (B) GP-1; (C) GE-1437; (D) GE-3885

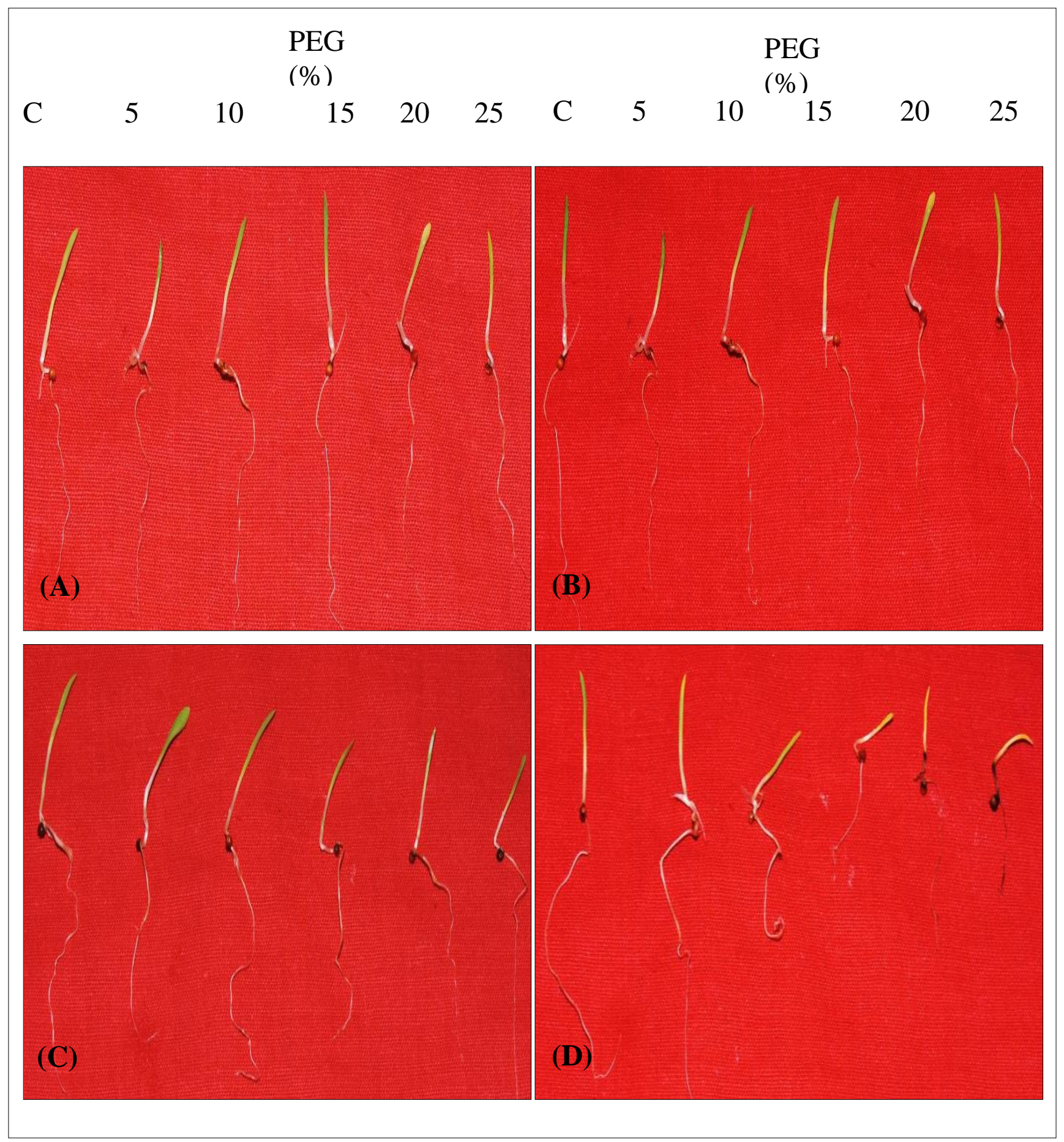


Figure.2 Effect of polyethylene glycol on physiology of seedlings (A) fresh weight, (B) root length, (C) shoot length and (D) relative water content of four different genotypes of finger millet. All values represent mean \pm SEM $(n=2)$. $P$ value versus GP-1: a $<0.001 ; b<0.01 ; c<0.05$; d, Not significant. $P$ value versus GP-45: $\mathrm{p}<0.001 ; \mathrm{q}<0.01 ; \mathrm{r}<0.05$; $\mathrm{s}$, Not significant. $P$ value versus GE-1437: A $<0.001$; $\mathrm{B}<0.01 ; \mathrm{C}<0.05$; D, Not significant. $P$ value versus GE-3885: $\mathrm{P}$ $<0.001 ; \mathrm{Q}<0.01 ; \mathrm{R}<0.05 ; \mathrm{S}$, Not significant.

(A)

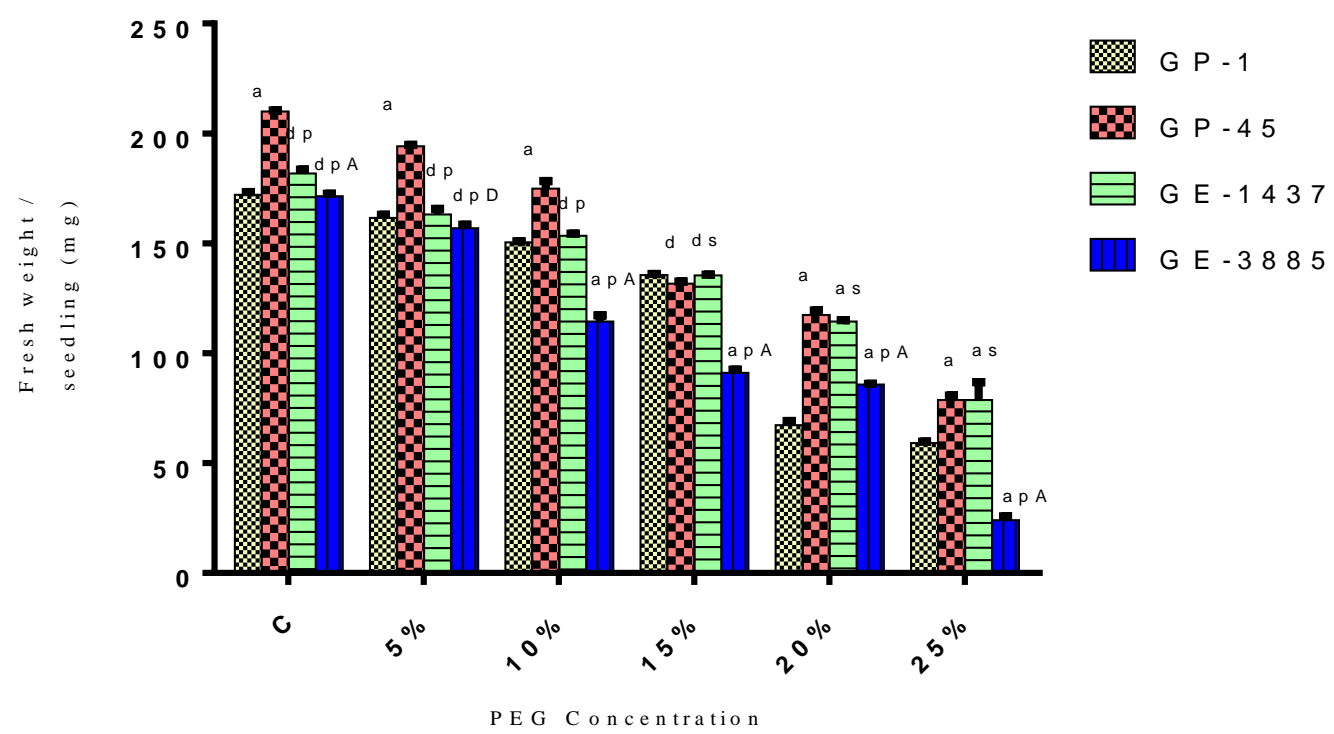

(B)

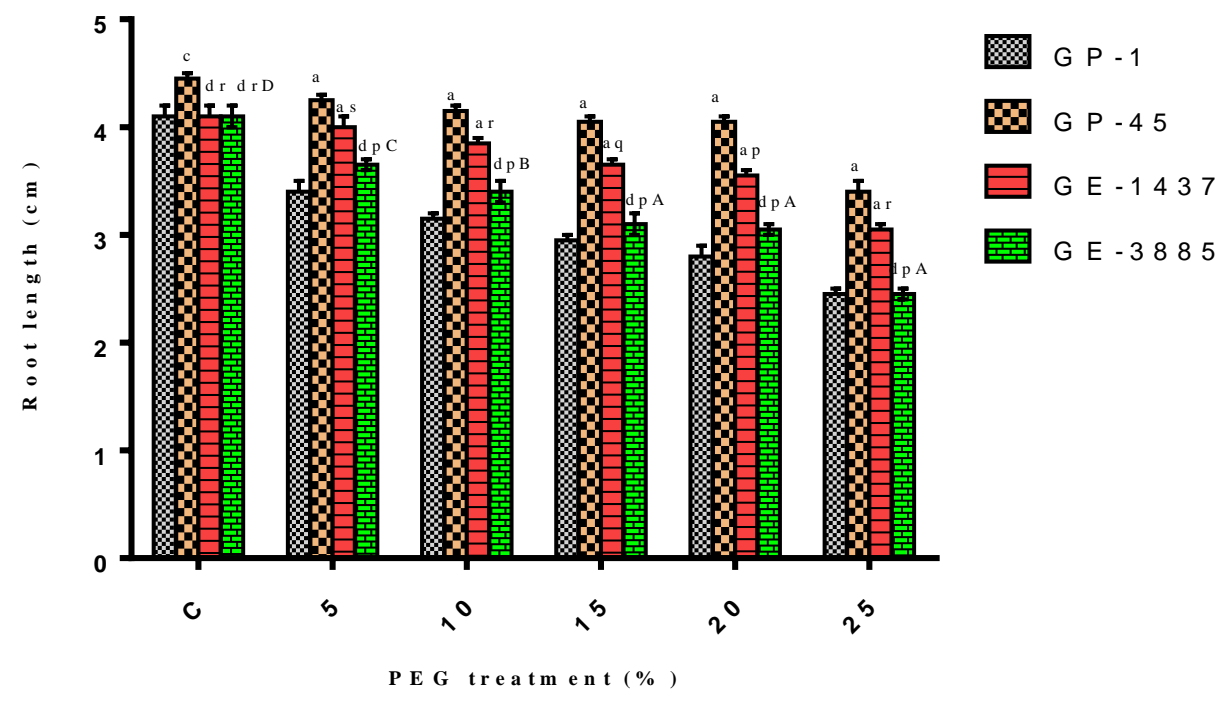


(C)

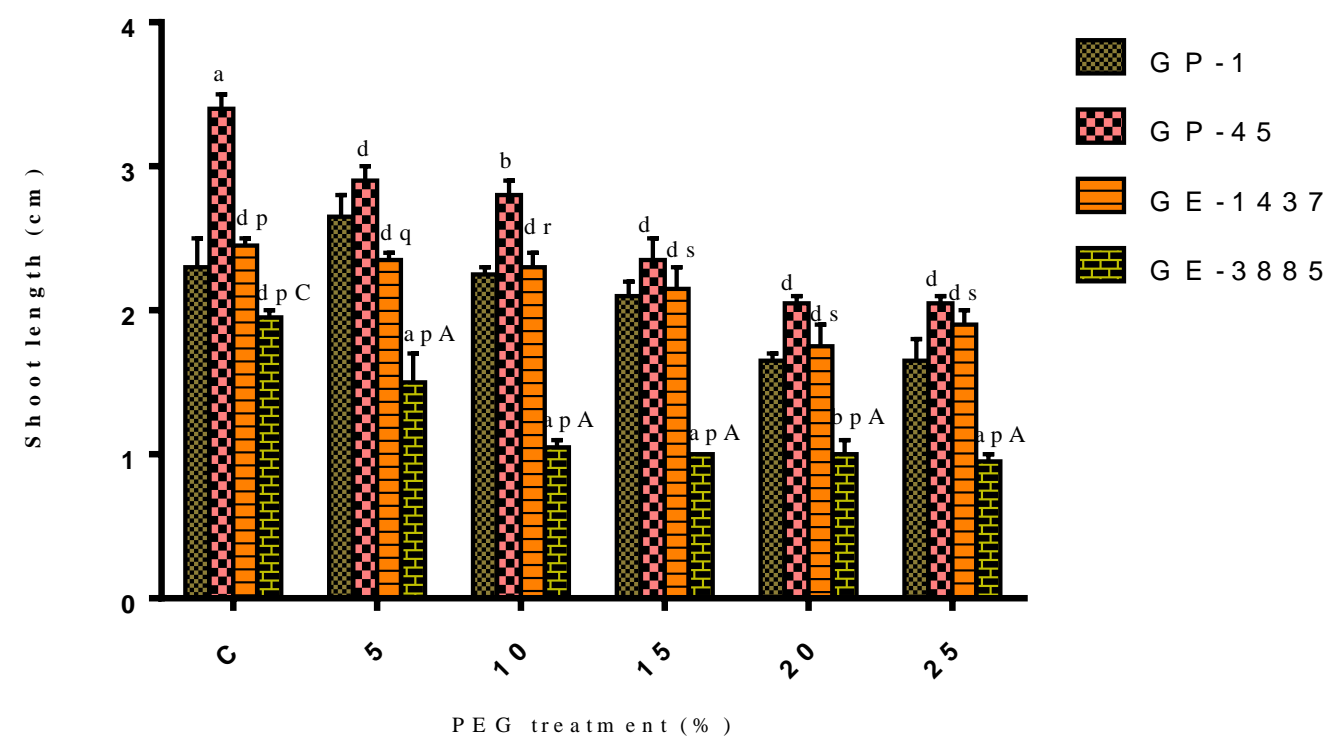

(D)

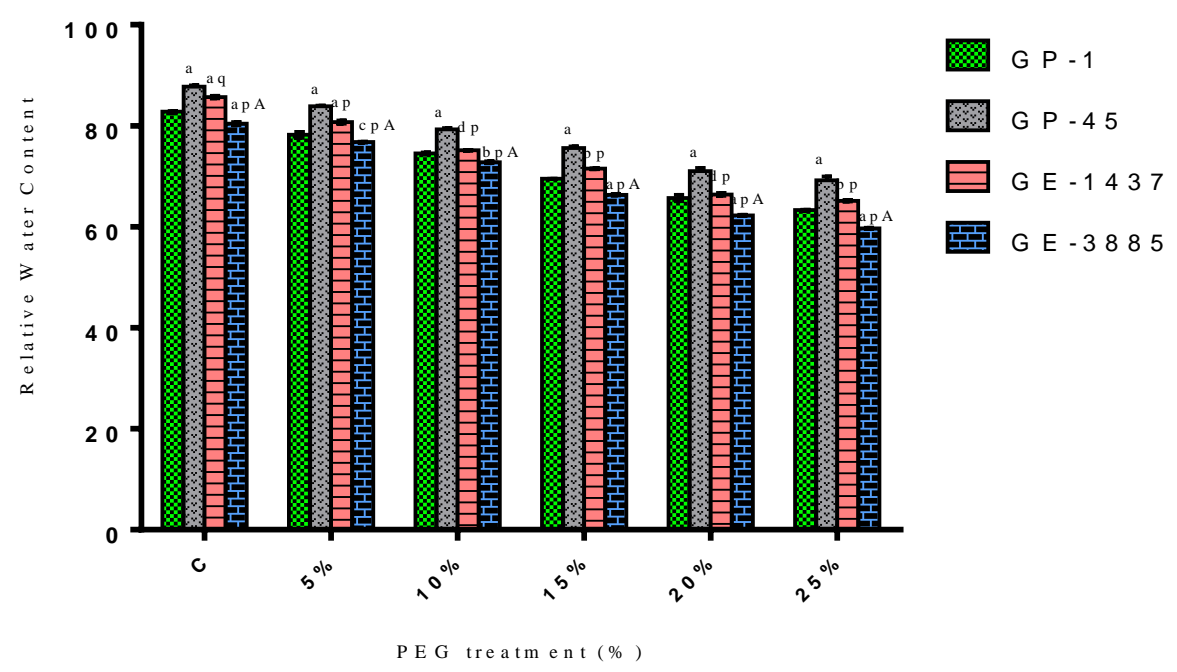


Figure.3 Effect of polyethylene glycol on antioxidant enzyme content (A) Catalase (CAT) (B)Guaiacol peroxidase (POD) (C)Ascorbate peroxidase (APX) and (D)Superoxide Dismutase (SOD)of four different genotypes of finger millet. All values represent mean \pm SEM $(n=2) . P$ value versus GP-1genotypes: a $<0.001$; $\mathrm{b}<0.01$; $\mathrm{c}<0.05$; d Not significant. $P$ value versus GP45: $\mathrm{p}<0.001 ; \mathrm{q}<0.01 ; \mathrm{r}<0.05$; s Not significant. $P$ value versus GE-1437: A <0.001; $\mathrm{B}<0.01 ; \mathrm{C}$ $<0.05$; D Not significant. $P$ value versus GE-3885: P <0.001; Q <0.01; R<0.05; S Not significant

(A)

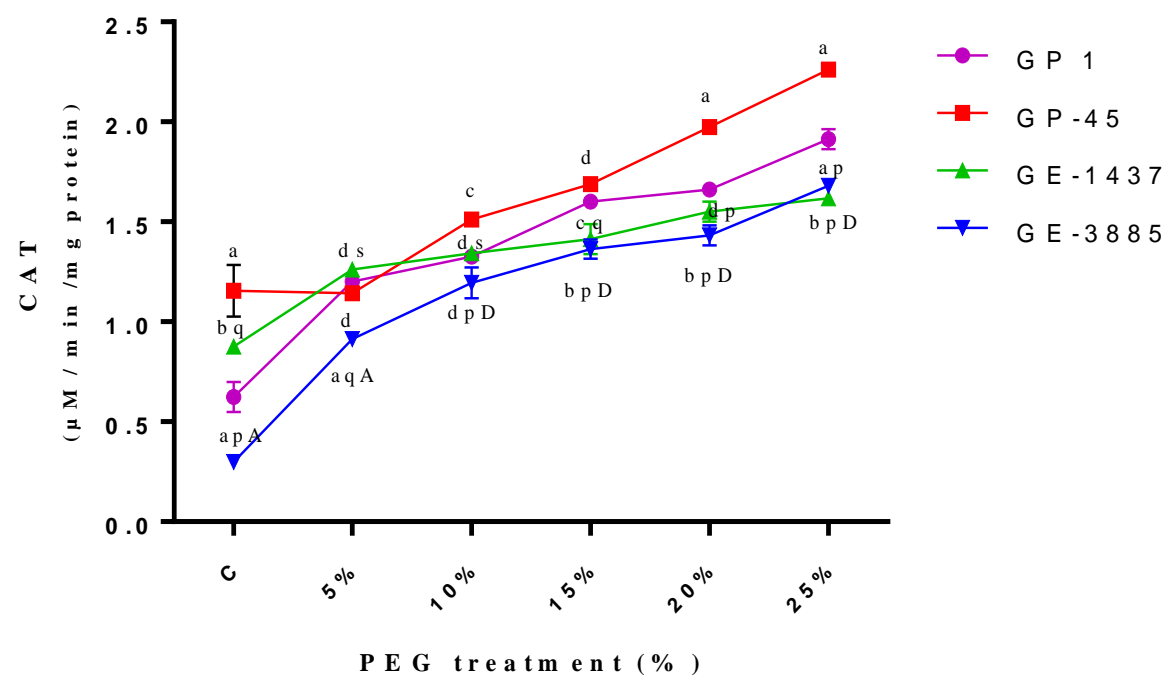

(B)

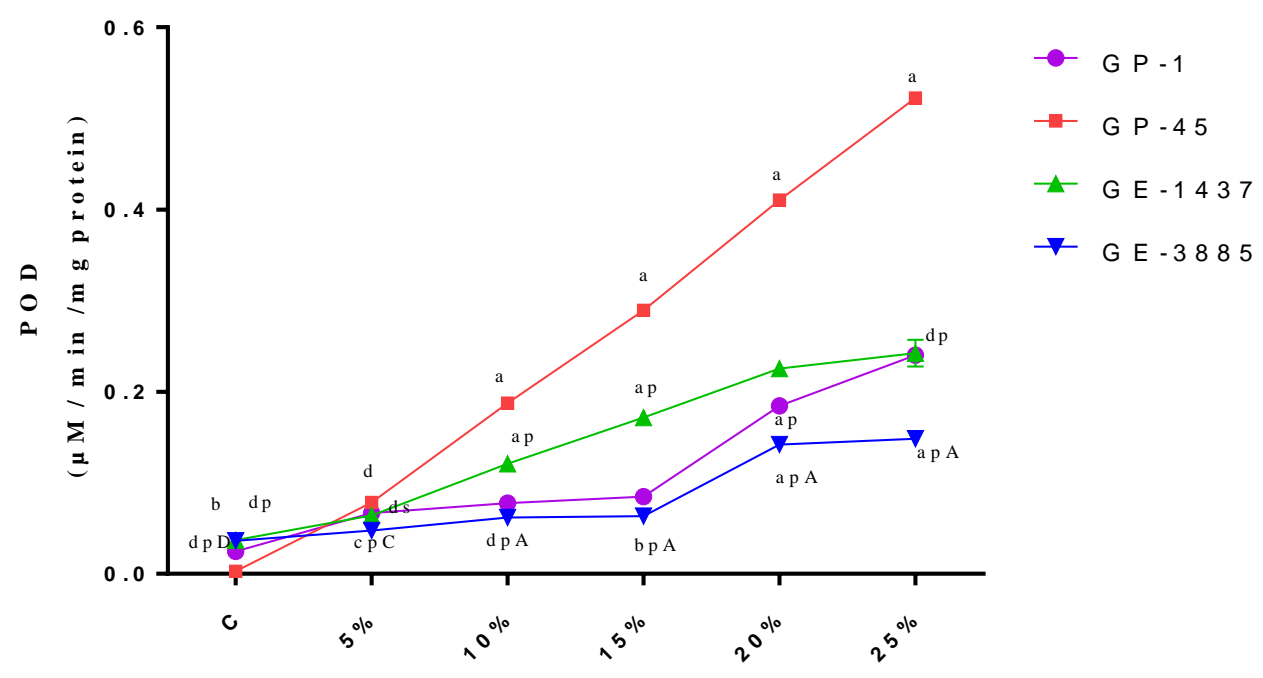

PEG treatm ent ( \% ) 
(C)

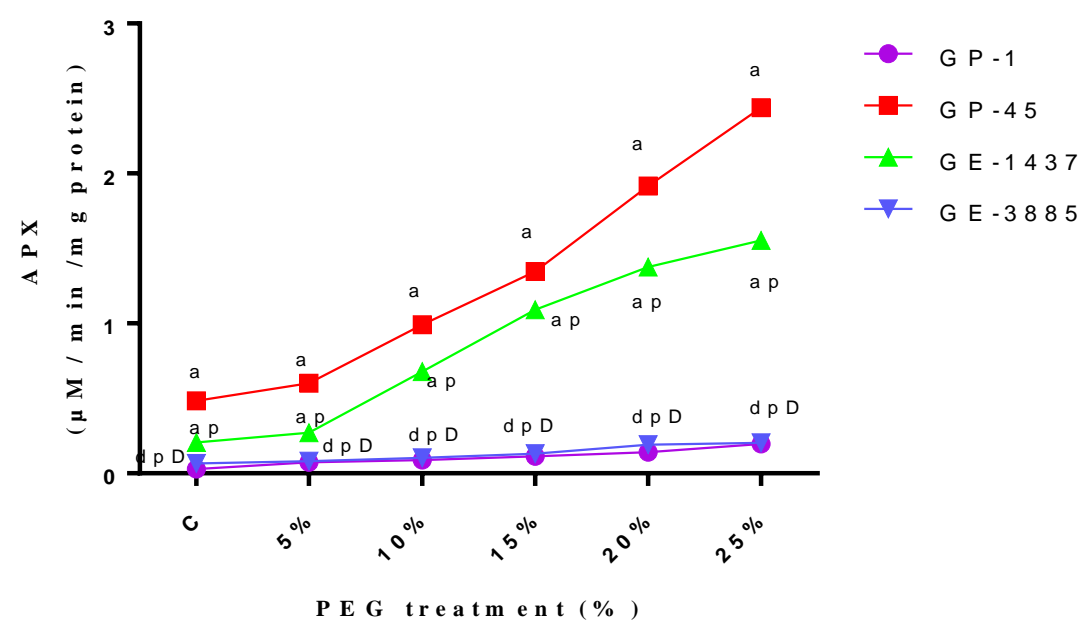

(D)

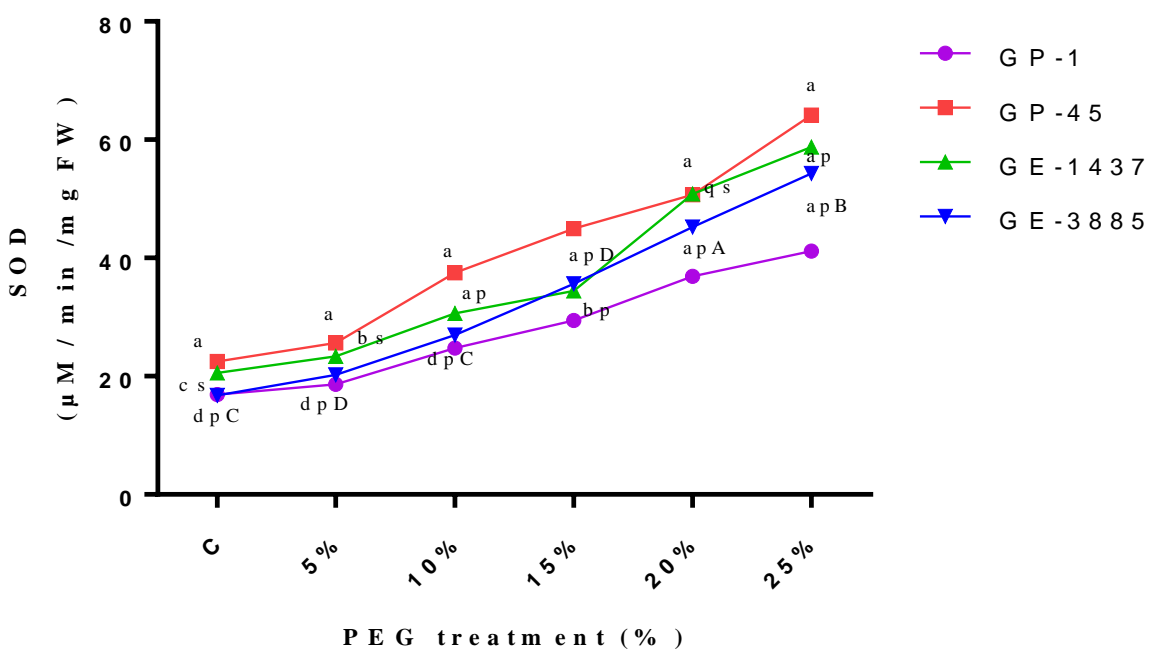

Drought stress invokes disruption in intracellular water content and affects the plant physiologically, leading to growth inhibition, impaired photosynthesis and biochemical changes like disruption of ion homeostasis, generation of ROS, etc. (Wojtyla et al., 2020). With increasing drought stress, there is elevation in the osmotic pressure of soil solution which can lead to cell dehydration, shortage of water, plant wilting and ultimately death of plant (Farooq, 2009). PEG interrupts the pathways for water movement and reduces water absorption leading to desiccation of the plants (Lawlor, 2010). It is, therefore, widely used to induce artificial drought in many plant systems (Basal et al., 2020; Hellal et al., 2018; Moura di et al., 2016; Jatoi et al., 2014). Better insight of biochemical responses, has lead crop improvement 
programs towards generation of drought tolerant varieties. For sustainable agriculture, it is very important to identify drought tolerant genetic resources (Khan et al., 2019). Sensitivity or tolerance in plants is regulated with intrinsic antioxidant reactions; tolerant cultivars deplete the oxidative stress burst via enhancement in antioxidant enzyme activity (Saud et al., 2016, 2017).

Characterization has been carried out for the four finger millet genotypes, at seedling stage, for their stress tolerance in response to drought stress indices in-vitro. Previous report suggested that the degree of calcium accumulation was higher in GP-45 root, stem and leaf $(337.8 \mathrm{mg} / 100 \mathrm{~g})$ and lower in GP-1 $(47.5 \mathrm{mg} / 100 \mathrm{~g})$ genotypes of finger millet (Nath et al., 2013). GE 3885 and GE 1437 have been reported to contain 13.76 and $6.15 \%$ grain protein content (Kanwal et al., 2014). The genotypes GP-45 and GE-1437 having high calcium and low protein content were tolerant to drought stress whereas the genotypes GP-1 and GE-3885 with low calcium and high protein content were sensitive (unpublished data of our lab). Calcium has been reported to improve the adverse impacts of water stress on plants (Jaleel et al., 2007) and is involved in signalling anti-drought responses (Shao et al., 2008). This may suggest that the tolerance and sensitivity to water stress at seedling stages is a result of constitutional nutrient composition and other metabolites during seed development and is conserved throughout a plant's different life stages.

Prior reports have demonstrated that drought stress impeded seedling growth because of blocked cell expansion and reduction in carbon partitioning and accumulation (Jabbari et al., 2013). Some studies have also revealed that on exposure to stress induced by drought, plants can improve water deficit and nutrient use efficiency by reducing production of biomass and partitioning more biomass to root, resulting in a higher root-shoot $(\mathrm{R} / \mathrm{S})$ ratio (Zhang et al., 2018). Recently, Khan et al., 2019 reported decrease in root and shoot lengths during PEG induced osmotic stress in rapeseed genotypes. Our results are in agreement with previous reports that on increasing water deficit the fresh weight and shoot length significantly decrease with tolerant phenotype showing better physiological response as compared to the sensitive ones (Mukami et al., 2019). According to Tavakol and Pakniyat (2007) and Boldaji et al., (2012) varieties tolerant to drought have an instinctive allocation of root biomass under stress induced by drought whereas it was not obvious in droughtsensitive genotypes.

To evaluate the degree of dehydration, cellular water merit in finger millet seedlings under PEG-mediated water scarcity was quantified as RWC. Many reports have distinguished the crops genotypes as sensitive and tolerant on the basis of RWC (Hojati et al., 2011; Boughalleb and Hajlaoui 2011). It shows the ability of conserving cellular hydration even under water deprivation via osmotic balance. Typical RWC during wilting is approximately $60-70 \%$ in most plant species (Sengupta and Lahiri Majumder 2009). PEG- mediated water deficit reduces RWC; here we showed that on increasing drought stress there was reduction in RWC in all four genotypes but not very significant. Recently, few reports on finger millet (Mukami et al., 2019) and rice (Shaoo et al., 2019) have demonstrated the decline in RWC caused reduced growth in response to osmotic stress. Under water deficit, sensitive finger millet genotypes were more affected by decline in RWC comparable to tolerant genotypes (Mukami et al., 2019). However, taking into account all physiological parameters give insight to further in-depth knowledge we had characterized drought 
stress biochemically via enzymatic oxidational potential.

The impact of water deficit on ROS level has been previously studied in several plant systems ( Miller, Suzuki, Ciftci-Yilmaz and Mittler, 2010; Noctor et al., 2014).This ROS generation is a result of metabolic disruptions, especially in organelles such as mitochondria, but also from the disruptions caused by ROS during cell signalling (Choudhury et al., 2017). Saux et al., (2020) have reported differences in the water stress-dependent accumulation of reactive oxygen species and antioxidant enzymes activities between sunflower hybrids. It has also been reported that status of ROS-mediated damage depends on homeostasis between ROS generation and activation of antioxidant defence mechanism (Mirzaee et al., 2013). In our results, activity of antioxidant enzymes CAT, SOD, POD and APX enhanced significantly however, higher antioxidant enzyme activity was noticeable in GP-45 and GE-1437, the tolerant genotypes while lower in GP-1 and GE-3885 (sensitive genotypes) with the increase in levels of ROS in seedlings of all the genotypes exposed to drought stress. During various abiotic stresses in tolerant genotypes, the level of antioxidant enzymes was more as comparable to sensitive genotypes (Turkan et al., 2005). Outcome of this study is in agreement with previous reports that mention higher SOD, CAT, APX and POD activity in drought tolerant genotypes of alfalfa (Wang et al., 2009) ,common bean (Turkan et al., 2005), finger millet( Bhatt et al., 2012;Bartwal and Arora, 2017) and rapeseed (Khan et al, 2019 This study, thus, suggests that physiomorphological and biochemical parameters can be used as selectable markers for selection of tolerant and sensitive genotypes on exposure to drought stress and could be used as proxy for evaluating plant drought tolerance in agronomy, breeding and genetic engineering for crop improvement.
In conclusion, the seedlings of four finger millet genotypes used in this investigation differed in their morpho-physiological and biochemical responses on imposition of water stress. Morpho-physiological responses were found to be significantly reduced in terms of fresh weight, root length and shoot length with increasing water stress. Moreover, enhanced antioxidant enzyme activity during water stress induced antioxidant defence mechanism. Based upon physiological and biochemical strategies, GP-45 and GE-1437 the tolerant genotypes showed highest CAT, POD, APX and SOD activity in comparison to GP-1 and GE-3885 the susceptible varieties which showed reduced tolerance and low enzyme activity. These results may suggest that calcium and protein components influence the tolerant genotypes by maintaining ROS and providing osmoprotectant homeostasis during osmotic stress. The future prospects would involve better assessment of tolerant and susceptible phenotypes and genotypes based on the detailed study of molecular mechanisms involved in drought responsiveness which can form the basis of improvement of varieties more adapted to drought conditions.

\section{Acknowledgements}

The authors wish to acknowledge Department of Biotechnology, Govt. of India for providing financial support (project code 7069) and fellowship during the period of study. I would also gratitude to Dr.Israr Ahmed and N. Pavithran for help and support.

\section{References}

Asaeda, T., Sanjaya, K. and Kaneko, Y., 2017.Effects of mechanical stressors caused by mean flow and turbulence on aquatic plants with different morphologies. Ecohydrology, 10(5), p.e1873.

Askari, E. and Ehsanzadeh, P., 2015. Drought 
stress mitigation by foliar application of salicylic acid and their interactive effects on physiological characteristics of fennel (Foeniculum vulgare Mill.) genotypes. ActaPhysiologiaePlantarum, 3 7(2), p.4.

Bartwal, A. and Arora, S., 2017. Drought stressinduced enzyme activity and mdar and apx gene expression in tolerant and susceptible genotypes of Eleusine coracana (L.). In Vitro Cellular \& Developmental Biology-Plant, 53(1), pp. 41-49.

Basal, O., Szabó, A. and Veres, S., 2020. Physiology of soybean as affected by PEG-induced drought stress. Current Plant Biology, p.100135.

Beers, R.F. and Sizer, I.W., 1952. A spectrophotometric method for measuring the breakdown of hydrogen peroxide by catalase. J Biolchem, 195(1), pp.133-140.

Bhatt, D., Negi, M., Sharma, P., Saxena, S.C., Dobriyal, A.K. and Arora, S., 2011. Responses to drought induced oxidative stress in five finger millet varieties differing in their geographical distribution. Physiology and Molecular Biology of Plants, 17(4), p.347.

Boldaji, S.H., Khavari-Nejad, R.A., Sajedi, R.H., Fahimi, H. and Saadatmand, S., 2012. Water availability effects on antioxidant enzyme activities, lipid peroxidation, and reducing sugar contents of alfalfa (Medicago sativa L.). ActaPhysiologiae Plantarum, 34(3), pp.1177-1186.

Bor, M., Özdemir, F. and Türkan, I., 2003. The effect of salt stress on lipid peroxidation and antioxidants in leaves of sugar beet Beta vulgaris L. and wild beet Beta maritima L. Plant Science, 164(1), pp.7784.

Boughalleb, F. and Hajlaoui, H., 2011. Physiological and anatomical changes induced by drought in two olive cultivars (cv Zalmati and Chemlali). ActaPhysiologiae Plantarum, 33(1), pp.53-65.

Boyer, J.S., 1982.Plant productivity and environment. Science, 218(4571), pp.443448.

Bradford, M.M., 1976. A rapid and sensitive method for the quantitation of microgram quantities of protein utilizing the principle of protein-dye binding. Analytical biochemistry, 72(1-2), pp.248-254.

Choudhury, F.K., Rivero, R.M., Blumwald, E. and Mittler, R., 2017. Reactive oxygen species, abiotic stress and stress combination. The Plant Journal,90(5), pp.856-867.

Dhindsa, R.S., Plumb-Dhindsa, P. and Thorpe, T.A., 1981. Leaf senescence: correlated with increased levels of membrane permeability and lipid peroxidation, and decreased levels of superoxide dismutase and catalase. Journal of Experimental botany, 32(1), pp.93-101.

Farooq, M., Wahid, A., Kobayashi, N., Fujita, D.B.S.M.A. and Basra, S.M.A., 2009. Plant drought stress: effects, mechanisms and management. In Sustainable agriculture (pp. 153-188).Springer, Dordrecht.

Gupta, S.M., Arora, S., Mirza, N., Pande, A., Lata, C., Puranik, S., Kumar, J. and Kumar, A., 2017. Finger millet: a "certain" crop for an "uncertain" future and a solution to food insecurity and hidden hunger under stressful environments. Frontiers in Plant Science, 8, p. 643.

Gupta, A., Rico-Medina, A. and Caño-Delgado, A.I. 2020. The physiology of plant responses to drought. Science. 368(6488): 266-269.

Gupta, A., Rico-Medina, A. and Caño-Delgado, A.I., 2020. The physiology of plant responses to drought. Science, 368(6488), pp.266-269.

Hadiarto, T. and Tran, L.S.P., 2011. Progress studies of drought-responsive genes in rice. Plant cell reports, 30(3), pp.297310.

Hassan, N.S., Shaaban, L.D., Hashem, E.S.A. and Seleem, E.E., 2004. In vitro selection for water stress tolerant callus line of Helianthus annus L. Cv. 
Myak. International Journal of Agriculture and Biology, 6(1), pp.13-18.

Hellal, F.A., El-Shabrawi, H.M., Abd El-Hady, M., Khatab, I.A., El-Sayed, S.A.A. and Abdelly, C., 2018. Influence of PEG induced drought stress on molecular and biochemical constituents and seedling growth of Egyptian barley cultivars. Journal of Genetic Engineering and Biotechnology, 16(1), pp.203-212.

Hojati, M., Modarres-Sanavy, S.A.M., Karimi, M. and Ghanati, F., 2011. Responses of growth and antioxidant systems in Carthamus tinctorius L. under water deficit stress. Actaphysiologiae plantarum, 33(1), pp.105-112.

Jabbari, H., Akbari, G.A., Sima, N.A.K.K., Rad, A.H.S., Alahdadi, I., Hamed, A. and Shariatpanahi, M.E., 2013. Relationships between seedling establishment and soil moisture content for winter and spring rapeseed genotypes. Industrial Crops and Products, 49, pp.177-187.

Jagtap, V. and Bhargava, S., 1995.Variation in the Antioxidant Metabolism of Drought Tolerant and Drought Susceptible Varieties of Sorghum bicolor (L.) Moench. exposed to high light, low water and high temperature stress. Journal of Plant Physiology, 145(1-2), pp.195-197.

Jaleel, C.A., Manivannan, P., Sankar, B., Kishorekumar, A., Gopi, R., Somasundaram, R. and Panneerselvam, R., 2007. Water deficit stress mitigation by calcium chloride in Catharanthus roseus: Effects on oxidative stress, proline metabolism and indole alkaloid accumulation. Colloids and Surfaces B: Biointerfaces, 60(1), pp.110-116.

Jatoi, S.A., Latif, M.M., Arif, M., Ahson, M.U.H.A.M.M.A.D. and Siddiqui, S.U., 2014. Comparative assessment of wheat landraces against polyethylene glycol simulated drought stress. Science Technology and Development,33(1), pp.1-6.

Kanwal, P., Gupta, S., Arora, S. and Kumar, A., 2014. Identification of genes involved in carbon metabolism from Eleusine coracana (L.) for understanding their light-mediated entrainment and regulation. Plant cell reports,33(8), pp.1403-1411.

Khan, M.N., Zhang, J., Luo, T., Liu, J., Ni, F., Rizwan, M., Fahad, S. and $\mathrm{Hu}$, L., 2019.Morpho-physiological and biochemical responses of tolerant and sensitive rapeseed cultivars to drought stress during early seedling growth stage. ActaPhysiologiae Plantarum, 41(2), p.25.

Kumar, A., Metwal, M., Kaur, S., Gupta, A.K., Puranik, S., Singh, S., Singh, M., Gupta, S., Babu, B.K., Sood, S. and Yadav, R., 2016. Nutraceutical value of finger millet [Eleusine coracana (L.)Gaertn.], and their improvement using omics approaches. Frontiers in plant science, 7 , p.934.

Lawlor, D.W., Bruce, T., Foyer, C.H., Halford, N.G., Keys, A., Kunert, K., Parry, M.A.J. and Russell, G., 2010. How can plant science improve agricultural production in Africa. Proceedings of 'Agriculture: Africa's 'engine for growth'-plant science and biotechnology hold the key'. Aspects of Applied Biology, (96), pp.185194.

Lobell, D.B., Roberts, M.J., Schlenker, W., Braun, N., Little, B.B., Rejesus, R.M. and Hammer, G.L., 2014. Greater sensitivity to drought accompanies maize yield increase in the US Midwest. Science, 344(6183), pp.516-519.

Maharajan, T., Ceasar, S.A., Ajeeshkrishna, T.P., Ramakrishnan, M., Duraipandiyan, V., Naif Abdulla, A.D. and Ignacimuthu, S., 2018. Utilization of molecular markers for improving the phosphorus efficiency in crop plants. Plant Breeding, 137(1), pp.10-26.

Majumder, A.L., Sengupta, S. and Goswami, L., 2009. Osmolyte regulation in abiotic stress.In Abiotic Stress Adaptation in Plants (pp. 349-370).Springer, Dordrecht.

Miller, G.A.D., Suzuki, N., Ciftci- Yilmaz, S.U.L.T.A.N. and Mittler, R.O.N., 2010. Reactive oxygen species homeostasis and 
signalling during drought and salinity stresses. Plant, cell \& environment, 33(4), pp.453-467.

MIRZAI, M., Moeini, A. and Ghanati, F., 2013. Effects of drought stress on the lipid peroxidation and antioxidant enzyme activities in two canola (Brassica napus L.) cultivars.

Mouradi, M., Bouizgaren, A., Farissi, M., Latrach, L., Qaddoury, A. and Ghoulam, C., 2016. Seed osmopriming improves plant growth, nodulation, chlorophyll fluorescence and nutrient uptake in alfalfa (Medicago sativa L.)-rhizobia symbiosis under drought stress. Scientia Horticulturae, 213, pp.232-242.

Mukami, A., Ngetich, A., Mweu, C., Oduor, R.O., Muthangya, M. and Mbinda, W.M., 2019. Differential characterization of physiological and biochemical responses during drought stress in finger millet varieties. Physiology and Molecular Biology of Plants, 25(4), pp.837-846.

Nakano, Y. and Asada, K., 1981. Hydrogen peroxide is scavenged by ascorbatespecific peroxidase in spinach chloroplasts. Plant and cell physiology, 22(5), pp.867-880.

Nath, M., Roy, P., Shukla, A. and Kumar, A., 2013.Spatial distribution and accumulation of calcium in different tissues, developing spikes and seeds of finger millet genotypes. Journal of plant nutrition, 36(4), pp.539-550.

Noctor, G., Mhamdi, A. and Foyer, C.H., 2014. The roles of reactive oxygen metabolism in drought: not so cut and dried. Plant physiology, 164(4), pp. 1636-1648.

Onaga, G. and Wydra, K., 2016. Advances in plant tolerance to abiotic stresses. Plant Genomics, pp.229-272.

Parvathi, M.S., Nataraja, K.N., Yashoda, B.K., Ramegowda, H.V., Mamrutha, H.M. and Rama, N., 2013. Expression analysis of stress responsive pathway genes linked to drought hardiness in an adapted crop, finger millet (Eleusine coracana). Journal of plant biochemistry and biotechnology, 22(2), pp.193-201.
Parvathi, M.S. and Nataraja, K.N., 2017. Discovery of stress responsive TATA-box binding protein associated Factor6 (TAF6) from finger millet (Eleusine coracana (L.) Gaertn). Journal of Plant Biology, 60(4), pp.335-342.

Ramakrishnan, M., Ceasar, S.A., Vinod, K.K., Duraipandiyan, V., Ajeesh Krishna, T.P., Upadhyaya, H.D., Al-Dhabi, N.A. and Ignacimuthu, S., 2017. Identification of putative QTLs for seedling stage phosphorus starvation response in finger millet (Eleusine coracana L. Gaertn.) by association mapping and cross species synteny analysis. PloS one, 12(8), p.e0183261.

Saha, D., Gowda, M.C., Arya, L., Verma, M. and Bansal, K.C., 2016.Genetic and genomic resources of small millets. Critical Reviews in Plant Sciences, 35(1), pp.56-79.

Sahoo, S., Saha, B., Awasthi, J.P., Omisun, T., Borgohain, P., Hussain, S., Panigrahi, J. and Panda, S.K., 2019.Physiological introspection into differential drought tolerance in rice cultivars of North East India. Acta Physiologiae Plantarum, 41(4), p.53.

Saux, M., Ponnaiah, M., Langlade, N., Zanchetta, C., Balliau, T., El- Maarouf- Bouteau, H. and Bailly, C., 2020. A multiscale approach reveals regulatory players of water stress responses in seeds during germination. Plant, Cell \& Environment, 43(5), pp.1300-1313.

Shanker, A.K., Maheswari, M., Yadav, S.K., Desai, S., Bhanu, D., Attal, N.B. and Venkateswarlu, B., 2014. Drought stress responses in crops. Functional \& integrative genomics, 14(1), pp.11-22.

Shao, H.B., Song, W.Y. and Chu, L.Y., 2008. Advances of calcium signals involved in plant anti-drought. Comptesrendus biologies, 331 (8), pp.587-596.

Sharma, D., Jamra, G., Singh, U.M., Sood, S. and Kumar, A., 2017. Calcium biofortification: three pronged molecular approaches for dissecting complex trait of 
calcium nutrition in finger millet (Eleusine coracana) for devising strategies of enrichment of food crops. Frontiers in plant science, 7 , p.2028.

Tardieu, F., 2012. Any trait or trait-related allele can confer drought tolerance: just design the right drought scenario. Journal of experimental botany, 63(1), pp.25-31.

Tavakol, E. and Pakniyat, H., 2007. Evaluation of some drought resistance criteria at seedling stage in wheat (Triticumaestivum L.) cultivars. Pak. J. Biol. Sci, 10(7), pp.1113-1117.

Uma, S., Prasad, T.G. and Kumar, M.U., 1995.Genetic variability in recovery growth and synthesis of stress proteins in response to polyethylene glycol and salt stress in finger millet. Annals of Botany, 76(1), pp.43-49.

Wang, W.B., Kim, Y.H., Lee, H.S., Kim, K.Y., Deng, X.P. and Kwak, S.S., 2009.
Analysis of antioxidant enzyme activity during germination of alfalfa under salt and drought stresses. Plant Physiology and Biochemistry, 47(7), pp.570-577.

Wojtyla, Ł., Paluch-Lubawa, E., SobieszczukNowicka, E. and Garnczarska, M., 2020. Drought stress memory and subsequent drought stress tolerance in plants. In Priming-Mediated Stress and CrossStress Tolerance in Crop Plants (pp. 115131). Academic Press.

You, J. and Chan, Z., 2015.ROS regulation during abiotic stress responses in crop plants. Frontiers in plant science, 6 , p.1092.

Zaharieva, T., Yamashita, K. and Matsumoto, H., 1999. Iron deficiency induced changes in ascorbate content and enzyme activities related to ascorbate metabolism in cucumber roots. Plant and cell physiology, 40(3), pp.273-280.

\section{How to cite this article:}

Gautam Jamra, Pallavi Shah, Aparna Agarwal, Divya Sharma and Anil Kumar. 2020. Elucidating the Physio-Morphological and Biochemical Responses towards PEG-Induced Drought Stress in Finger Millet Genotypes. Int.J.Curr.Microbiol.App.Sci. 9(07): 1672-1687. doi: https://doi.org/10.20546/ijcmas.2020.907.193 